\title{
Bringing older informal caregivers and recipients to the digital age: Experiences of using digital services
}

\author{
Sirpa Salin* and Hannele Laaksonen \\ School of Health Care, Tampere University of Applied Sciences, Tampere, Finland
}

\begin{abstract}
.
BACKGROUND: Advancing informal caregivers' and recipients' health and functional capacity and enabling living at home are significant objectives in Finnish society. The purpose of this project is to create a model for supporting the welfare services of informal caregivers digitally.

METHOD: The data were collected in late 2017 by interviewing the informal caregivers $(N=19)$ who took part in the project in one city $(n=9)$ and one rural municipality $(n=10)$. They filled the $15 \mathrm{D}$ quality of life instrument with added questions before and after intervention and evaluated the digital service after seven months of piloting. The recipients $(n=19)$ also filled a questionnaire on a memory game device.

RESULTS: Informal caregivers considered their quality of life good, though approximately half felt mildly depressed and distressed. Their wishes for tablet programs included peer support, lectures, and live entertainment. Nearly all caregivers recommended the digital service to others despite technical problems. The difficulty of the game divided the recipients' opinions. A functional service model is presented as a summary of the project.

CONCLUSIONS: It is paramount to move the entire service to a single platform with large shortcuts to each segment. This will enable the user to easily use the programs and contact people.
\end{abstract}

Keywords: Informal caregiver, recipient, digitalization, quality of life

\section{Introduction/background}

According to estimates, 1.2 million Finns sometimes care for their close ones and approximately 350000 of them are their primary caretaker [1]. Informal caregivers are an economically significant resource, as their work significantly lessens the costs of social services and affect the costs of healthcare services [2].

Over the past three decades, there have been many studies of informal caregivers. Topics include their backgrounds, their needs for support, and intervention programs that have aimed to meet their needs [3]. Most informal caregivers are the retired spouses of

\footnotetext{
* Corresponding author: Sirpa Salin, School of Health Care, Tampere University of Applied Sciences, Kuntokatu 3, Tampere 33520, Finland. Tel.: +358 505914540; E-mail: sirpa.salin@tuni.fi.
}

the recipient. Earlier studies show that their burden is greater than that of other informal caregivers, which also means a greater risk of health problems $[2,4]$. Informal caregivers describe their care relationship as a complex and emotional relationship of responsibility, which causes them several kinds of harm, such as physical exhaustion, feelings of hopelessness, lack of recognition and economic loss [5,6]. However, they also report experiencing positive effects, of which the most important are feelings of closeness to the recipient, improved self-respect and feeling appreciated for their work [6-8]. Even though there is a great deal of knowledge of informal caregivers' experiences of the care relationship, information about the effects of various intervention programs in improving their situations is still missing [9].

Schulz et al. [10] describe the recent development of technology as a digital revolution, which is shifting the 
balance from mechanical devices to digital technology. This will allow for the development and use of computers, smart phones, the Internet, robots and countless recognition and aid software to ease the lives of informal caregivers. The development of new technology is a challenge to informal caregivers, who will have to use more challenging technological devices [11] and perform more complex care procedures $[8,11]$. This study focuses particularly on supporting older informal caregivers through technological means.

There have been many studies of technologies supporting the elderly's living at home. Assistive technology was most often used for mobility, washing up, intimate hygiene and rising from bed [12]. Homes have been modified to allow for the independent performing of the above $[13,14]$. It is possible to make the home safe and accessible with the aid of technology. Safe home appliances, burglar alarms and emergency call devices are among the technological solutions that lead to better living at home according to the elderly $[15,16]$. The neighborhood is important in keeping the home supportive and safe $[17,18]$. Elderly people who maintained contact with their neighbors and community experienced their home and neighborhood as more positive than others and were able to live at home longer [17].

Chen and Schulz [19] conducted a literature review of ICT interventions that aimed to decrease the social isolation of elderly people. ICT was found to improve the amount of social support they received along with their connections with others, but its effect on experiences of loneliness remained unclear. Connections to the outside world, receiving social support, participating in interesting activities and improving self-esteem were important factors in lessening the elderly's social isolation and feelings of being an outsider. Informal caregivers' personal life is particularly in danger of becoming nothing more than caring for the recipient, especially when they need full-time care [19,20].

Studies show that elderly people also used IC technology in maintaining family relationships and as sources of information on health bulletins as well as various activities [1,16,21].

Highly educated people who lived with a spouse were most likely to use ICT. They also had a positive attitude towards technology, whereas non-users experienced it as threatening and stressful [22].

Even though the elderly are seen as a growing customer group, only a few service producers have created solutions from their point of view [15]. A thorough knowledge of the context in which the technolo- gies are used in the design and research phases is instrumental in gaining the acceptance of the market and the users [23]. The "Bringing older informal caregivers and recipients to the digital age project" reported in this study had informal caregivers and recipients develop digital welfare services together with various experts.

The overall goal of the project was to produce a support model for older informal caregivers' welfare services. The project assessed the suitability of two digital services, a communication and leisure application and a game application, for improving the target audience's quality of life after a seven-month pilot period. This article describes the pilot group's quality of life and their experiences of the services.

\section{Purpose and aim}

The purpose of this study was to describe one city and one rural municipality's older informal caregivers' quality of life, digital capabilities, interest and experiences in digital services as a part of everyday life and the recipients' experience of the memory game.

This study answers the following questions:

1. How do informal caregivers perceive their quality of life before and after intervention?

2. What is the informal caregivers' assessment of the digital services after the intervention?

3. What is the recipients' assessment of the memory game device?

4. What kind of a digital service model would best support older informal carers?

\section{Description of the intervention}

The intervention contained the following services delivered through tablet computers, which were provided by the project: 1) live broadcasts twice per week (eg. meditation, chair yoga, chair exercises, balance exercises) 2) informational videos on YouTube and 3) zoom virtual meetings. The subjects chose a live broadcast activity that appealed to them and initially committed to it for two months. After this, they were given a chance to choose a new activity. Many however chose to continue the same one for the entire pilot stage. The Informational videos were produced by the researchers, based on topics requested by the informal caregivers. Their lengths varied between ten to fifteen minutes and discussed topics such as memory illnesses, the proper diet for a Marevan patient and 
the use of medicine. The researchers produced thirty videos, which the subjects could watch at their leisure through a link saved on the tablet's front page. The virtual Zoom meetings were organized weekly. The subjects spoke about topics chosen by themselves with other group members. There were two groups, one for the rural and one for the urban subjects. Even though these programs were intended for the informal caregivers, the recipients were welcome to participate in all but the Zoom meetings. Many of the couples did participate in the programs together.

The project also tested the memory game Memoera, which is a Finnish game device developed for people with memory illnesses. It has been designed to be easy to use and to activate multiple brain functions and senses simultaneously through quizzes and games (https://memoera.fi/). Each test subject received a device for the seven-month duration of the pilot stage. Even though the game was intended for the recipients, the informal caregivers were encouraged to play the game with them.

\section{Research data and methods}

\subsection{Collecting data and participants}

The research data were collected in late 2017 and after the seven month pilot period in 2018 by interviewing the informal caregivers $(N=19)$ who took part in the research project in one city $(n=9)$ and one rural municipality $(n=10)$. The intention of the project was to have ten couples from both locations, but one couple in the city group had to leave the project due to the recipient's hospitalization. Nurses who had performed physical examinations for the elderly recruited the informal caregivers. The targeted informal caregivers all cared for an elderly recipient at home full-time. The informal caregivers consented to taking part in the experiment in writing and gave their contact information. They were subsequently contacted by researchers via phone to agree on a date for a meeting at their home before the start of the pilot phase.

The informal caregivers started by completing a 15D quality of life questionnaire, after which the instrument's questions were discussed in greater depth in a semi-structured interview. The themes were chosen from the WHOQOL - BREF instrument, which gave more detailed information about the informal caregivers' experiences of life, health and relationships and their computer skills, interest in digital services, and their possibilities in improving everyday life. The lengths of the interviews varied from 45 minutes to two hours. The interviews were recorded and transcribed later.

After the intervention, the informal caregivers completed the same $15 \mathrm{D}$ quality of life questionnaire. They were also asked about their experience of the digital service through a questionnaire created by the researchers. The recipients completed a questionnaire about their experience with the memory game.

\section{2. $15 D$ - quality of life instrument}

The international 15D quality of life instrument (http://15d-instrument.net/15d/) used in the study contains the following variables: mobility, vision, hearing, breathing, sleeping, eating, speech, excretion, usual activities, mental function, discomfort and symptoms, depression, distress, vitality and sexual activity. The variables are graded on a five-point scale of $1=$ normal operating capacity, $2=$ mild difficulties, $3=$ quite a bit of difficulty, $4=$ great difficulties and $5=$ unable.

\subsection{Analyzing the data}

The data from the semi-structured interviews were analyzed using data-based content analysis and theming [24]. The analysis was started by reading the data, after which the text was listed under the various themes and grouped in subcategories. The subcategories were combined into main categories. Questions related to digitalization and its possibilities were themed according to contents. The results are presented here as percentages and frequencies. Due to the small size of the sample $(N=19)$ no statistical analyses were performed. The data were analyzed by the two researchers (SS and HL) who had conducted the interviews. The data were saved as an Excel file.

\section{Results}

\subsection{Informal caregivers' quality of life by $15 D$ instrument}

The informal caregivers' ages ranged from 61 to 88 . Fifteen of them were female and five men. They all cared for their spouse at home. Nearly all of the care recipients had a memory illness.

Figure 1 shows the results of the caregivers' questionnaires as frequencies so that the first measurement 


\section{NORMAL AND MILD DIFFICULTIES}

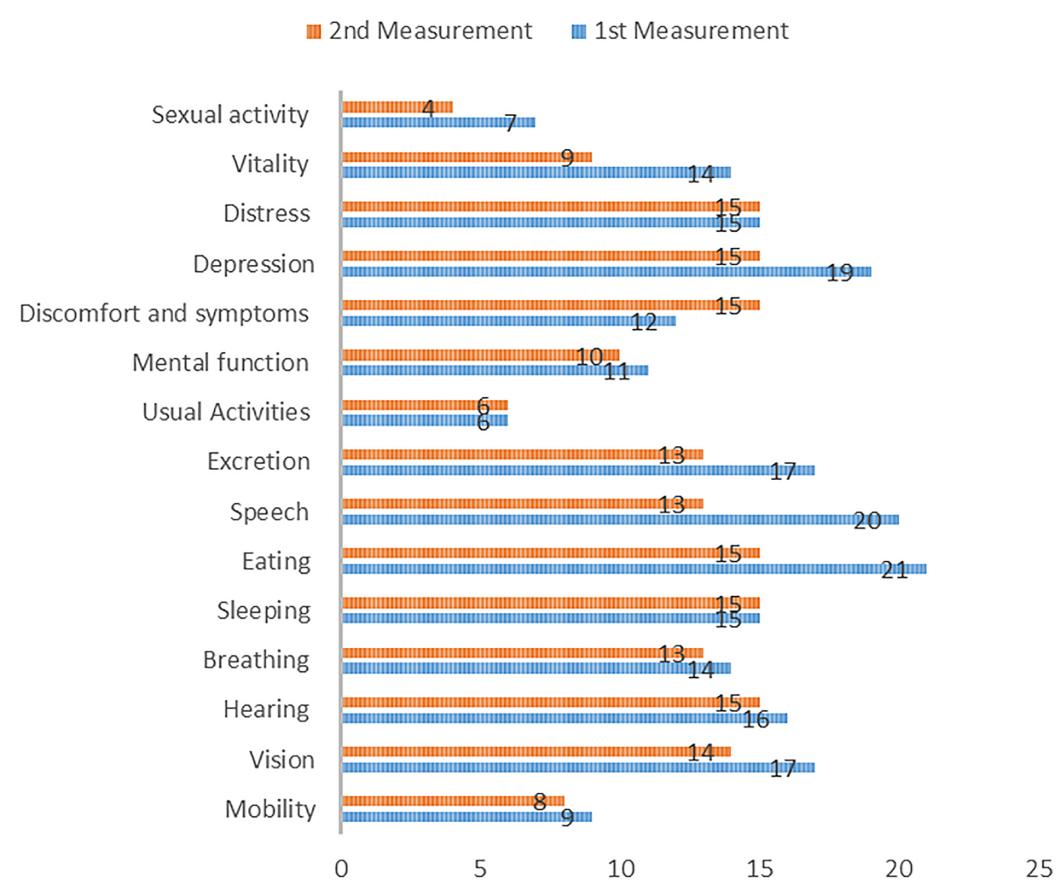

Fig. 1. The quality of life of the caregivers in the city and rural region 1st and 2nd measurements: Normal or Mild difficulties $(N=19)$.

shows the initial results and the second measurement shows the results after the intervention. The results show that mobility, eating, speech, mental functions, distress, vision and hearing have remained at the same level. Breathing, sexual activity, vitality, depression and usual activities have worsened mildly, while discomfort, symptoms, and sleep have improved mildly. The results show that changes during the period of approximately one year, positive and negative, remained mild.

\subsection{Informal caregivers' descriptions of their quality of life before the intervention}

\subsubsection{The experience of one's own health}

The caregivers suffered from several chronic diseases, which made them regular clients of the healthcare system. Some had cancer or multiple cancers, which were in remission. Their serious diseases did not however disturb their lives, as they either did not have pains or had successful treatments for them. One of the caregivers defined their own condition as "sickhealthy". Some of the caregivers were afraid of contracting a memory disease as they observed their spouse's condition. Most defined their own health as fairly good.

\subsubsection{Experiencing life as meaningful}

The meaning of the caregivers' lives consisted of taking care of their spouse's wellbeing, which took precedence over everything else. Children and their families brought them joy and life, and following the joys and sorrows of their family's lives was important. They were proud and grateful of their achievements in life, such as owning their home. Access to exercise was another concrete way of experiencing life as meaningful, which gave them a sense of freedom and which they no longer took for granted as in their youth.

Some had questioned the meaningfulness of life recently because of their spouse's sudden illness or its worsening. They felt that life had lost meaning and that nothing mattered.

\subsubsection{Relationships with friends and satisfaction in them}

The caregivers had friends, with whom they went walking, took part in hobbies and talked on the phone. Some had friends from their work, with whom they 
had maintained contact. The couples also had common friends, even though many were no longer part of their life, either due to the spouse's illness or because they had relocated. Many kept close contact with childhood friends, whose spouses had also become their common friends over the years.

Losing friends because of the spouse's illness was a cause for bitterness. Friends could no longer see the person with a memory illness as a normal person, which was painful for the caregiver to see.

"I felt insulted for my wife in some situations and didn't want to visit them anymore...people don't change because of an illness... it's not like you can catch it from her"

Some friendships had also ended because the friend had developed a memory illness. Some still maintained contact, even though the friend could no longer recognize the interviewees. The caregivers' own children and their families had become increasingly important in their lives and spent much time with the caregivers. Neighbors were also important as friends who could help in everyday tasks and offer support. Peer support groups were sources of new friends, whose support was appreciated. The caregivers described their spouse as their most important friend, as they spent all their time together and did everything together. The spouses knew each other well after their long marriages and did not always need words.

\subsubsection{Enjoying life}

Taking a vacation from their everyday lives was one way of enjoying life. Some of the couples visited a warm country to the south annually, for which they waited and planned together. The lengths of the visits ranged from a week to months. Friendships born during their travels were cherished and meeting their friends again was a highlight of their trips.

The caregivers said that they had previously traveled often, but no longer had the energy as the illness advanced. They still planned trips together with their spouse, which brought them both joy. Spending time with friends was important and brought variation to their days. The caregivers appreciated having their own home and their ability to continue living in it. Life was good as long their days were normal, their bills were paid on time and there was food in the refrigerator.

The couples were busy with their activities. They did not even have time to think about enjoying life. One of the caregivers expressed it in the following way:

"I'm so awful busy that I don't even have time to think"
A bad relationship between the spouses could hinder their enjoyment of life. The spouses spent all their time together, which could put a strain on their relationship, particularly as the spouse's illness advanced. The caregivers wished for more social interactions and activities outside the home. Their spouse's advancing illness also forced the caregivers to take responsibility for everything, which strained their relationship and caused exhaustion. The caregivers had to learn new things such as completing electronic forms.

\subsubsection{Experience of safety \\ Internal safety}

Some caregivers' sense of internal safety was threatened by a fear of having a seizure and not receiving help. The fears were caused by an earlier horrific experience, of which they still had nightmares years later. They still thought about the possibility of unforeseen events and their own helplessness. They also had to comfort their spouse, who feared something would happen to the caregiver and its effect on themselves.

"I panic at night and the feeling grows, and I can't sleep.”

The caregivers sometimes had to fear the recipient's unpredictable behavior. The recipient's distress sometimes caused them to act in unpleasant ways and make threats, which caused a sense of unsafety. Female caregivers in particular felt unsafe, as they had to take responsibility for everything as their spouse's condition declined.

\section{External safety}

Caregivers' sense of external safety was increased by living in a peaceful, familiar environment with neighbors who had lived there for decades. They were always willing to help each and kept an eye on each other in a positive way. Some neighborhoods had become less peaceful, which could be seen in e.g. people locking their doors at daytime. Nearby families with children brought a sense of safety. Some of the caregivers and their spouses had had to move to a new apartment after the spouse's illness. Their new modern, well-equipped homes increased their sense of safety.

\subsubsection{Experience of receiving information}

Caregivers thought they received enough information, although it required their own activity and curiosity. Information was available if they asked. Their main sources of information were the Internet, magazines and books. The information they needed was avail- 
able online, or they had people they could ask. Peers were an important source of information, particularly in matters related to legally guaranteed assistance and applying for it. Associations were also a source of current information related to their situation.

“... I give advice to anyone who asks. I hate how when social assistance decisions come, you first need to think if they made a mistake..."

There was also criticism of information reception. Their spouse's sudden illness and the changes in their life were experiences they would not forget. They had to manage on their own without oversight. One of the caregivers described the situation:

"... the episode came like a hit and it messed up everything. I mean all our plans went out the window at that moment, and no one helped. We'd been home alone together for a month before anyone came..."

\subsubsection{Possibility of concentrating}

The caregivers could focus on things when they had to. Paying bills online was a moment that required particular concentration. Other activities that were important to the caregivers, such as reading and solving crossword puzzles, were also possible without interruptions. The caregivers also spoke of the recipient interrupting and disturbing their activities. These situations led to arguments, which worsened the atmosphere at home. Some had sought outside help with improving their concentration. One had taken a stress management course, whose daily training exercises had improved the situation. Respite care gave the caregivers valuable time to perform tasks that required concentration.

Some caregivers always had the possibility of doing leisure activities. Others could do them a few hours at a time. Those who could do them with the recipient faced fewer limits. Some could only do them during the recipient's period of respite care.

\subsubsection{Possibility of being themselves}

The caregivers' responses to the topic of being themselves gave rise to three classes: being themselves, partially concealing their personality, and a conscious decision to be themselves. They compared not being themselves to acting which they could not do. They saw being themselves as a superior decision, even though it sometimes caused arguments and disharmony as the upset caregiver said things they later regretted. “...yes, sometimes too much. I yell and explode as necessary..."

Partially concealing their personality was a method of survival and maintaining hope. It involved presenting things as better than they were and hiding some things from the recipient. The caregiver had to consider their actions and words constantly. A formerly happy and laugh-filled way of looking at life had turned more serious.

\section{“... I have breaks on my laughter...”}

Some had briefly concealed themselves, e.g. after the discovery of the recipient's illness. Over time, they had however made a conscious decision to be themselves, because they considered acting otherwise burdensome.

“... I've decided...I'm who I am and I need to be accepted as slowed down or whatever else and that's that..."

\subsection{Informal caregivers' expectations for the digital project}

All informal caregivers knew how to use a computer and $14(N=19)$ reported being able to use it very well. Seven respondents could use a touch screen tablet very well. Half of the caregivers had participated in a video call on a computer and five had done so on a phone.

All informal caregivers used the computer daily for obtaining information and online banking. All had cell phones, most of which were smartphones. Some were already using tablets, but most were interested in learning to use one as part of the project. Their expectations for the pilot project included a change of pace, getting to know new people and keeping with new technologies. Curiosity was also a significant motivation. Wishes for live programs on the tablets included exercise programs such as chair gymnastics, yoga and balance exercises. They wished for specialist lectures on memory illnesses, musculoskeletal diseases and pain treatment. They were also interested in entertainment programs involving group singing and quizzes.

\subsection{Informal caregivers' experiences of digital services after the intervention}

\subsubsection{Communication and entertainment service}

Out of all informal caregivers, 89\% $(n=19)$ thought using the tablet was easy. Nonetheless, more 


\section{Informal caregivers' experiences of the service}

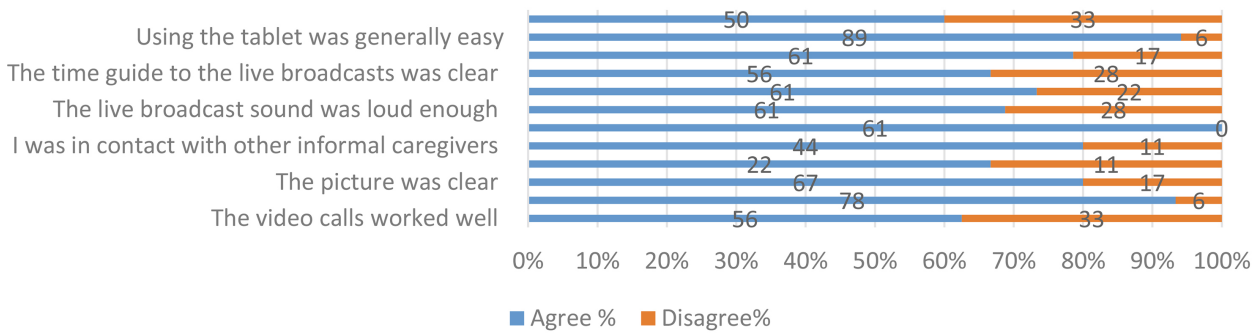

Fig. 2. Informal caregivers' $(n=19)$ experiences of the service.

\section{Informal caregivers' experiences of the YouTube videos}

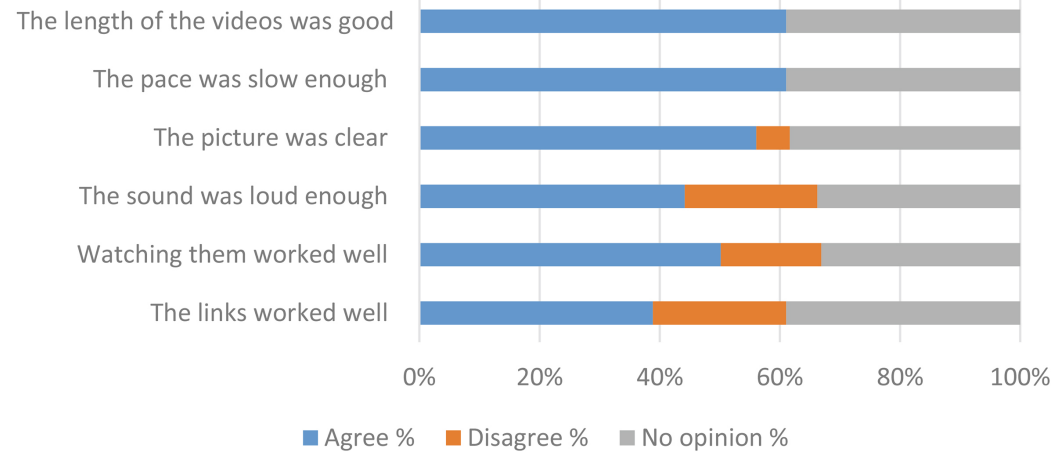

Fig. 3. Informal caregivers' $(n=19)$ experience of the YouTube videos.

than half reported needing help in using the service (Fig. 2). Almost all found making and receiving video calls on the tablet easy. Despite this, many preferred to communicate with their friends and family by using their smartphone or personal computer, to which they were accustomed. Most respondents considered the picture quality good.

\subsubsection{Video recordings}

The project created thirty informational videos that are viewable on a hidden YouTube playlist. Slightly more than half of the informal caregivers (56\%) viewed videos during the pilot stage, but statistics on YouTube show that they have continued watching the videos ( $n=292$ by 30 November 2018) after the end of the phase. More than half of the respondents thought that the videos were of a good length and had a slow enough pace. Approximately half of the viewers thought the picture was clear and that watching them worked well. The volume level was considered loud enough by $44 \%$ and $39 \%$ thought the links worked well (Fig. 3).
Some of the open responses hoped for a slowerpaced and calmer style of presentation. Some videos were difficult to understand because of inconsistent audio levels or unclear articulation.

\subsubsection{Live broadcasts}

The informal caregivers were generally satisfied with the contents of the live broadcasts. Many considered the exercise broadcasts their favorites and found the broadcasts well designed and executed. They also tried less familiar contents related to meditation and mental management, but did not find them as useful as the exercise programs. They were very happy with the lectures and question and answer programs held by experts. However, the caregivers found the schedules of the live broadcasts limiting and felt that they had to organize their time around them. They suggested that the broadcasts should be recorded and made viewable at a convenient time (Fig. 2).

Technical difficulties made viewing the broadcasts less pleasant, particularly for the rural group. Unstable Internet connections sometimes interrupted the broad- 


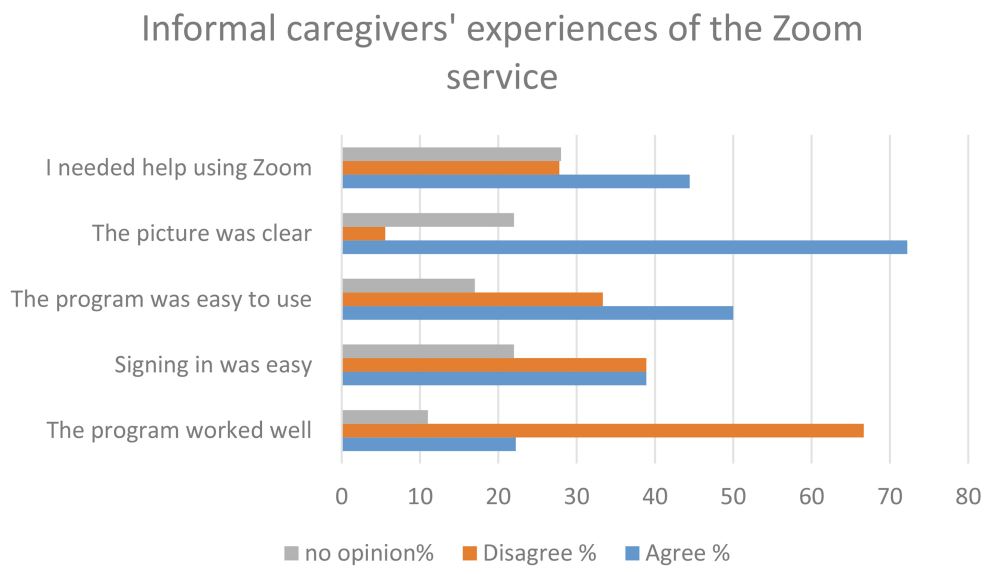

Fig. 4. Informal caregivers' $(n=19)$ experiences of the Zoom service.

\section{Recipients' experiences of Memoera}

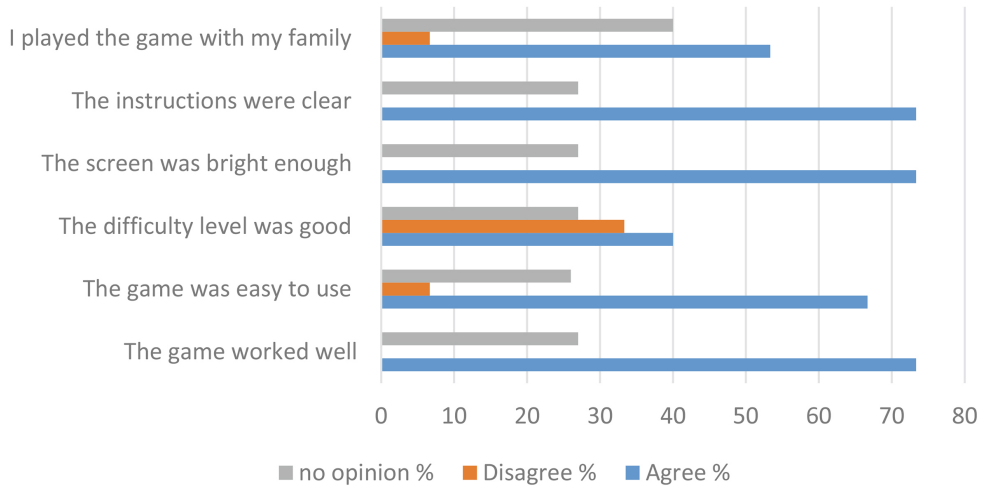

Fig. 5. Recipients' $(n=19)$ experiences of Memoera.

cast, which caused confusion and irritation. Sometimes promised programs were not broadcast. Overall, the caregivers were happy with the digital services and $86 \%$ would recommend the service to others once the technical problems were solved.

\subsubsection{The Zoom service}

Zoom virtual meetings were attended by $72 \%$ of the informal caregivers. One fifth thought the Zoom service worked well and half had trouble signing in to the service. One of the problems was a lack of instructions in Finnish. The rural group in particular had trouble reaching the intended topic, as problems with the technology became topics of discussion. The urban group considered the meetings successful and enjoyed meeting and befriending peers (Fig. 4).

One of the caregivers expressed the matter in the following way:

"or example, these Zoom conversations, they gave you that kind of peer support that you saw others were doing even worse and thought that your life still has ways to go before the bottom"

\subsubsection{The recipients' assessment of the memory game device}

The Memoera memory game device was played by $87 \%(n=19)$ of the recipients. The technical qualities of the device were seen as good, but the difficulty of the games divided opinions. Some considered them too easy while others found them just difficult enough. However, the games themselves worked well and were easy to use with their bright screens and clear instructions. The level of the player's memory illness was a determining factor in both their enthusiasm for the game and their experience of the game's easiness. Some recipients had to be reminded of the device or needed someone to play the games with them. Many found playing the games with their great-grandchildren 
a pleasant way to spend time. Many played the games daily, some less often and some not at all (Fig. 5).

All of the games shared one feature: the faster it was played, the faster the difficulty level rose. Those who found the games too easy might not have played fast enough, which might be why they were not enough of a challenge.

\section{Discussion}

Family and neighbors, volunteers and social and healthcare professionals are the main groups who assist informal caregivers in their work. Ways informal caregivers could benefit from technological services include having access to current information, maintaining relationships and receiving psychosocial support. Isolation and loneliness are major risks to informal caregivers' wellbeing and quality of life. As many are retirees themselves, they have a great risk of losing contact with the outside world as they focus on caring for the recipient. Their own aging can predispose them to physical and mental problems. They often have trouble sleeping, as they are responsible for the recipient even at night [4].

This study assessed the quality of life of informal caregivers via both the quantifying $15 \mathrm{D}$ instrument and interviews. The measurements, which were made before and after the intervention, show small changes which could not be tested statistically due to the small sample size. Usual activity, sexual activity and mobility were the weakest categories both before and after the intervention. Informal caregivers found life most meaningful through caring for the recipient. This study shows that recipients' worsening condition decreased informal caregivers' desire to live, while participating in various activities increased their sense of freedom and increased their welfare.

Informal caregivers had important relationships outside their home, as the neighborhood was important to their welfare. Many had spent decades in the same area and knew their neighbors as reliable figures who made them feel safe, as in the study by MacKenzie et al. [17]. Some couples had had to relocate to a more functional home in a new neighborhood, where they had however found a safety net with their new neighbors. Few of the caregivers considered themselves lonely or outsiders. This was partly because of their active, even busy lives outside the home. Technology cannot replace genuine human relationships as stated in the study by Jännes et al. [15], but individual technological solutions can sup- port and maintain social life. As technology enables rapid contact with one's friends and family, it can improve one's sense of safety and quality of life in e.g. situations where informal caregivers cannot participate in activities outside their home as much as they would want. Some of the informal caregivers in this study felt too tied to their home and wished for more freedom and personal time.

Losing earlier friendships was a factor that caused sorrow. The caregivers could not understand why their spouse's illness had made friends abandon them. This can be understood as friends not knowing how to behave around the recipient or what to talk about, particularly if they know nothing about the recipient's illness. Discussing the topic openly with friends could increase understanding and prevent abandonment. Their number of friends had also decreased over the years as their friends had died. One of the goals of this project was to help the caregivers form new friendships with peers in the same situation, for which the intervention offers a good platform. According to the systematic literary review conducted by Dam's research group [16], support given by informal caregivers' age-mates, social networks, support groups, either in person via remote access, is important. Their literature review suggest that diverse forms of support are the most efficient way of achieving social support and welfare goals. According to earlier studies [20,21] informal caregivers found respite in online communities and received emotional support through them. This study's findings on the necessity of peer support reinforce earlier findings.

According to Torp et al. [25], informal caregivers benefited from increasing technological information and messaging services, as using the services gave them more social connections, support and information about chronic illnesses and their treatments. Participants in the study were particularly appreciate of peer support. The intervention also increased their communication with friends and family. Information and communication technology can thus be said to have potential in increasing the welfare of informal caregivers of aging spouses.

All the informal caregivers in this study could already use a computer and a cell phone regardless of their educational background. It appears that the digital project attracted caregivers who were already familiar with IC technology. They knew how to search for information on the Internet and how to apply it to their needs. Contrary to this, Farshchian and Dahl's study [23] found that post-secondary education or living with a partner correlated with more active use 
of information and communication technology among those aged 65-70. The majority of the respondents in their study [2] used information and communication technology to maintain social connections and to obtain health-related information, as was also found in this study. Differences in results between studies performed in different countries can be affected by cultural factors and different levels of development. Finnish elderly people use information technology actively, as the governmental statistics institution Statistics Finland has found that $75 \%$ of those aged $65-74$ use the Internet regularly and $43 \%$ use it several times per day. Out of this age group, 33\% use the Internet via smartphone. People older than this use information technology less, but even of those aged 75-89, $37 \%$ use the Internet regularly. No difference in the amount of Internet use between men and women has been found [26].

In this study many also made video calls with their friends and family and considered it an important way of participating in their lives. The results support those of Chen and Schulz [19], who found that digital services enable forming connections to the outside world, receiving social support, participating in interesting hobbies and increasing self-confidence. One of the sources of stress faced by the caregivers were the new duties they had to bear due to their spouse's illness. It was difficult for them to assume responsibility for the family finances and their online management along with all their other tasks. Receiving outside support in their stressful situation is extremely important to their welfare. As they constantly live with the recipient's illness, the informal caregiver needs personal time outside home to feel refreshed and empowered.

Out of the informal caregivers participating in the project, $83 \%$ would recommend the project's digital services to others despite the technical difficulties. This service was recommended particularly to informal caregivers and lonely elderly people, who either cannot leave their home or live in sparsely populated areas with few services and neighbors and friends. The devices and the programs did not always function well, leading to situations like missed or interrupted live broadcasts. This was vexing, as many had canceled other activities for the live broadcasts. The caregivers generally found the schedule of the live broadcasts inflexible and suggested that they be made available to watch afterwards. While this would be more convenient, it would also defeat the purpose of interactive live broadcasts. The people working on the project could not help with all of the problems faced by the informal caregivers, as they were part-time employees. Continuing the service after this project would require enough clients to enable the hiring of a project coordinator. They could also provide rapid assistance with technical difficulties. The services in this project were bought from an established Finnish company, which is why the service was assumed to work without difficulties. Some of the broadcast interruptions were due to slower broadband connections in rural areas, some due to difficulties with the company.

Even though all the informal caregivers regularly use a computer, they still reported needing more technical support with the devices than they received from the researchers. The result supports Carretero et al.'s [4] finding that informal caregivers need a great deal of technological knowledge and support in using services. This project relied excessively on their capability and did not sufficiently consider their need for support. The Zoom service in particular never worked properly in the rural area, despite much effort. Many wanted the virtual peer support, as it is a good way of maintaining social relationships. The results support earlier studies, which have found that informal caregivers require both emotional and technical support $[4,10]$.

The informal caregivers were happy about the chance to use a tablet. The project gave them an opportunity to learn how to use it, along with other new things. The couples appreciated the chance to participate in the project and thought it was important to advance the cause of informal caregivers through projects such as this one. They were also glad for the chance to become acquainted with other informal caregivers.

Nearly half of the informal caregivers made a video call to another informal caregiver through the tablet. Nearly all thought that making and receiving video calls was easy. The researchers also wrote text messages that were visible on the tablet screen, but the caregivers could not themselves send or receive text messages. One topic of feedback was the lack of a notification for a missed video call, which the caregivers thought could cause misunderstandings. The device did not ring long enough, which sometimes made the caregivers miss calls. They were directed to always keep the device plugged to the charger, which caused vexation, as the cord of the charger was too short. Figure 6 shows a summary of the intervention's results.

The YouTube videos focused on topics requested by the informal caregivers and aimed to provide information based on latest research in a brief and accessible form. Information provided through health technology 


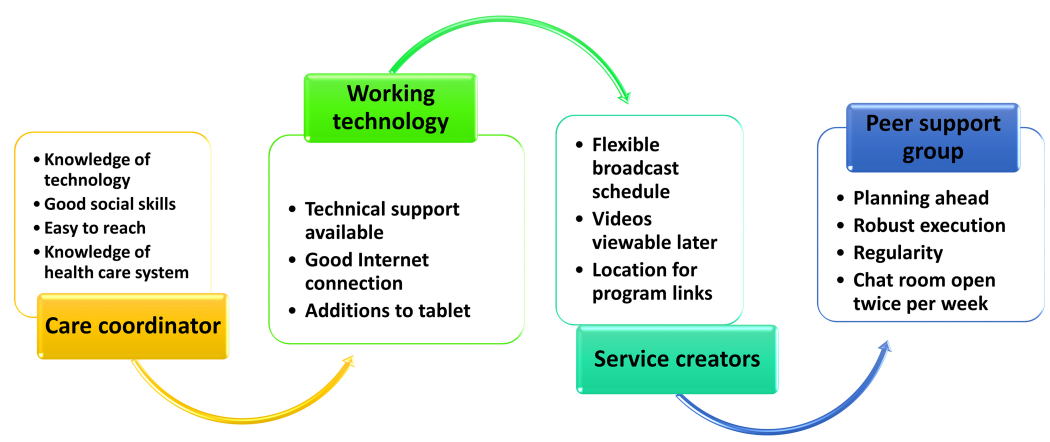

Fig. 6. Summary of the seven-month intervention's results.

\section{Platform for Digital Services}
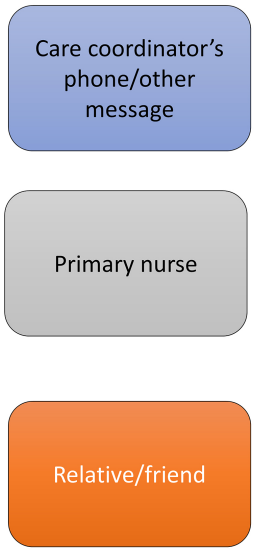
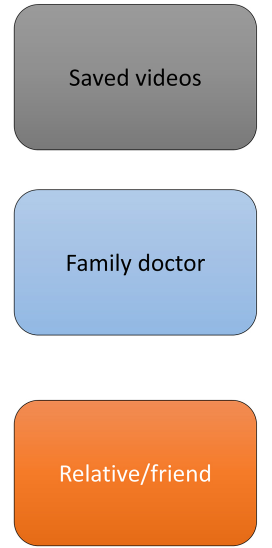
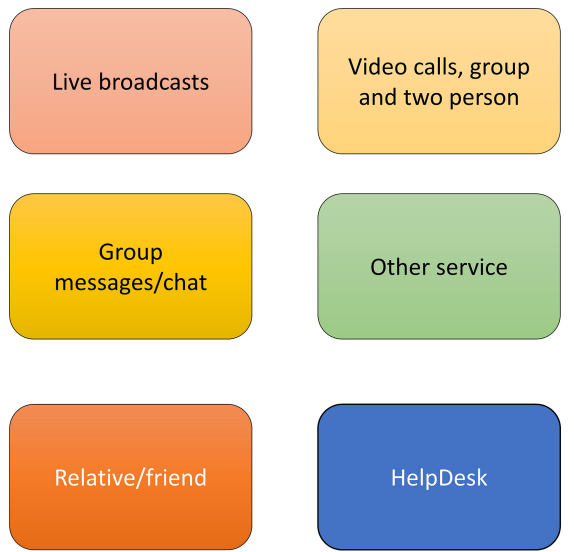

Fig. 7. Platform for digital services.

has been found to help informal caregivers to understand the illnesses of the people they are caring for and to manage the stress of providing care [21]. The videos are still viewable on the hidden playlist, whose URL was provided to all the subjects of the projects. Some caregivers did not watch the videos at all, while some found them a useful source of information. The quality and technical execution of the videos must be higher in the future.

\section{Limitations}

In this study the informal caregivers completed the validated $15 \mathrm{D}$ quality of life instrument, which has been tested internationally for over twenty years. Its reliability and validity have been assessed as good. Due to the small size of the respondents, it was not considered expedient to create the profile offered by the instrument. However, the questionnaire served as a good introduction to the semi-structured interviews, which delved deeper into the caregivers' everyday lives. The themes of the interview were chosen in cooperation with the project's experts and were taken directly from The World Health Organization's quality of life assessment (WHOQOL - BREF). The topics of the interviews were kept loose so that the caregivers' own experiences could emerge freely. The interviews became discussions and the caregivers forgot they were participating in a study [24].

Content analysis was performed by both researchers, as both had experience in the study of informal caregivers. This was done to ensure that the researcher's own prior understanding did not affect the interpretation of the results [24]. The goal has been to describe the analysis closely enough that the reader can follow the decisions made by the researchers.

The researchers interviewed 19 informal caregivers, which is a small number. These results were intended as a basis for planning the digital intervention in the 
project's pilot stage and are not meant to be generalized.

\section{Ethical considerations}

The research project and the associated choice of topic is based on the demanding and changing role of informal caregivers as the recipient's helper. The results can be used directly in advancing the welfare of informal caregivers. The permission for the study was granted by the ethical boards of the participating city and municipality.

The subjects participated in the study willingly and were told orally and in writing about the purpose of the study and what would be done with the information they provided. The covering letter given to them emphasized the voluntary nature of their participation, the confidentiality of the interviews and the anonymity of the analysis. The interviewer's name and contact information were included in the letter and the caregivers were encouraged to contact them if they needed more information. The protocol of the Declaration of Helsinki of the World Medical Association [27] was followed throughout the research process.

\section{Further research}

In further development of the service, it is paramount to move the entire service to a single platform with large shortcuts to each segment. These shortcuts would enable the user to easily use the programs and contact people. There should be shortcuts to the service coordinator, members of the peer group, some friends and family members and if necessary, their nurse or doctor. All these people would require a phone and video connection and the option of sending and receiving messages. Saved information videos and live broadcasts would have their own shortcuts. The audio design should have sufficiently loud and long tones for phone calls, text messages and live broadcasts. The home page should be made easier to understand by using clearer colors. Figure 7 shows a possible model of organizing the service.

\section{Conflict of interest}

The authors have no conflict of interest to report.

\section{References}

[1] Statistical information on welfare and health in Finland, Sotkanet. 2014; https://sotkanet.fi/sotkanet.

[2] Kehusmaa S, Autti-Rämö I, Rissanen P. Omaishoidon vaikutus ikääntyneiden hoidon menoihin. Yhteiskuntapolitiikka. 2013; 78(2): 138-151. In Finnish.

[3] Montgomery R, Kosloski K. Caregiving as a process of changing identity: implications for caregiver support. Journal of the American Society on Aging. 2009; 7(1): 47-52.

[4] Carretero S, Stewart J, Centerno C, Barbabella F, Schmidt A, Lamontagne-Godwin F, Lamura G. Can Technology-based Services support Long-term Care Challenges in Home Care? Analysis of Evidence from Social Innovation Good practices across the EU: CAICT Project Summary Report. European Union 2012, Luxembourg.

[5] Stoltz P, Udén G, Willman A. Support for family carers who care for an elderly person at home. A systematic literature review. Scandinavian Journal of Caring Science. 2004; 18(2): 111-119.

[6] Salin S, Kaunonen M, Åstedt-Kurki P. Informal carers of older family members. How they manage and what support they receive from respite care. Journal of Clinical Nursing. 2009; 18(4): 492-501.

[7] Pinquart M, Sörensen S. Associations of stressors and uplifts of caregiving with caregiver burden and depressive mood: a meta-analysis. The Journals of Gerontology Series B: A Psychological Sciences and Social Sciences. 2003; 58(2): 112128.

[8] McKee KJ, Philp I, Lamura G. The COPE index. A first stage assessment of negative impact, positive value and quality of support of caregiving in informal carers of older people. Aging Ment Health. 2003; 7(1): 39-52.

[9] Joling K, van Marwijk H, Smit F, van der Horst H, Scheltens $\mathrm{P}$, van de Ven P, Mittelman M, Hein PJ, van Hout H. Does a family meetings intervention prevent depression and anxiety in family caregivers of dementia patients? A randomized trial. PLoS One. 2012; 7(1): e30936. Open access.

[10] Schulz R, Wahl H-W, Matthews J, De Vito Dabbs A, Beach $\mathrm{S}$, Czaja S. Advancing the aging and technology agenda in gerontology. The Gerontologist. 2015; 55(5): 724-734.

[11] Palm E. Who cares? Moral obligations in formal and informal care provision in the light of ICT-based home care. Health care analysis: HCA. Journal of Health Philosophy and Policy. 2013; 21(2): 171-188.

[12] Anderson WL, Wiener JM. The Impact of assistive technologies on formal and informal home care. Gerontologist. 2015; 55(3): 422-433.

[13] Bishop M, Dennis K, Bishop K, Sheppard-Jones K, Bishop F, Frain $\mathrm{M}$. The prevalence and nature of modified housing and assistive devices use among Americans with multiple sclerosis. Journal of Vocational Rehabilitation. 2015; 42: 153-165.

[14] Mortenson W, Demers L, Fuhrer M, Jutai J, Lenker J, DeRuyter F. Development and preliminary evaluation of the caregiver assistive technology outcome measure. Journal of Rehabilitation Medicine. 2015; 47(5): 412-418.

[15] Jännes J, Hämäläinen P, Hanski J, Lanne M. Homelike living for elderly people: a needs-based selection of technological solutions. Home Health Care Management \& Practice. 2016; 27(2): 64-72.

[16] Dam A, de VugtInge M, Klinkenberg I, Verhey F, van Boxtel M. A systematic review of social support interventions for caregivers of people with dementia: are they doing what they promise? Maturitas. 2016; 85: 117-130. 
[17] MacKenzie L, Curryer C, Byles JE. Narratives of home and place findings from the Housing and Independent Living Study. Aging \& Society. 2015; 35(8): 1684-1712.

[18] Topo P. Tukeeko fyysinen ympäristö ja teknologia muistisairasta ihmistä? Gerontologia. 2015; 29(4): 221-235. In Finnish. Abstract in English.

[19] Chen Y-R, Schulz P. The effect of information communication technology interventions on reducing social isolation in the elderly: a systematic review. Journal of Medical Internet Research. 2016; 18: e18.

[20] Scharett E, Madathil K, Lopes S, Rogers H, Agnisarman S, Narasimha S, Ashok A, Dye C. An investigation of the information sought by caregivers of alzheimer's patients on online peer support groups. Cyberpsychology, Behavior, and Social Networking. 2017; 20(10): 640-657.

[21] Núñez-Naveira L, Alonso-Búa B, de Labra C, Gregersen R, Maibom K, Mojs E, Krawczyk-Wasielewska A, MillánCalenti JC. UnderstAID, an ICT platform to help informal caregivers of people with dementia: a pilot randomized controlled study. BioMed Research International. 2016; 2016: 113
[22] Vroman K, Sajay A, Lysack C. Who over 65 is online? Older adults' dispositions toward information communication technology. Computers in Human Behavior. 2015; 43: 156-166.

[23] Farshchian B, Dahl Y. The role of ICT in addressing the challenges of age-related falls: a research agenda based on a systematic mapping of the literature. Personal and Ubiquitous Computing. 2015; 19(3-4): 649-666.

[24] Hsieh HF, Shannon SE. Three approaches to qualitative content analysis. Qualitative Health Research. 2005; 15(9): $1277-$ 1288.

[25] Torp S, Hanson E, Hauge H, Ulstein I, Magnusson L. Pilot study of how information and communication technology may contribute to health promotion among elderly spousal carers in Norway. Health and Social Care in Community. 2008; 16(1): 75-85.

[26] https://www.stat.fi/til/sutivi/2017/13/sutivi_2017_13_201711-22_tie_001_en.html.

[27] World Medical Association Declaration of Helsinki. Available at: http://www.wma.net/en/20activities/10ethics/10helsinki/ index.html, accessed 5 September 2018. 